\title{
Transcultural Study of Postnatal
}

\section{Depression (TCS-PND): development and}

\section{testing of harmonised research methods}

EDITED BY M. N. MARKS, M. W. O'HARA, N. GLANGEAUD-FREUDENTHAL,

N. GUEDENEY, C. M. KLIER, B. FIGUEIREDO, P. BENVENUTI and J. L. COX

sl Introduction: Professor Channi Kumar (1938-2000)

M. N. Marks

s3 Aims, measures, study sites and participant samples of the Transcultural Study of Postnatal Depression

P. Asten, M. N. Marks, M. R. Oates and the TCS-PND Group

slo Postnatal depression across countries and cultures: a qualitative study M. R. Oates, J. L. Cox, S. Neema, P. Asten, N. Glangeaud-Freudenthal, B. Figueiredo, L. L. Gorman, S. Hacking, E. Hirst, M. H. Kammerer, C. M. Klier, G. Seneviratne, M. Smith, A.-L. Sutter-Dallay, V. Valoriani, B. Wickberg, K. Yoshida and the TCS-PND Group

sI7 Adaptation of the Structured Clinical Interview for DSM-IV Disorders for assessing depression in women during pregnancy and post-partum across countries and cultures

L. L. Gorman, M. W. O'Hara, B. Figueiredo, S. Hayes, F. Jacquemain, M. H. Kammerer, C. M. Klier,

S. Rosi, G. Seneviratne, A.-L. Sutter-Dallay and the TCS-PND Group

s24 Contextual Assessment of the Maternity Experience: development of an instrument for cross-cultural research

O. Bernazzani, S. Conroy, M. N. Marks, K. A. Siddle, N. Guedeney, A. Bifulco, P. Asten, B. Figueiredo, L. L. Gorman, S. Bellini, E. Glatigny-Dallay, S. Hayes, C. M. Klier, M. H. Kammerer, C. A. Henshaw and the TCS-PND Group

s31 Maternal attachment style and depression associated with childbirth: preliminary results from a European and US cross-cultural study

A. Bifulco, B. Figueiredo, N. Guedeney, L. L. Gorman, S. Hayes, M. Muzik, E. Glatigny-Dallay, V. Valoriani, M. H. Kammerer, C. A. Henshaw and the TCS-PND Group

s38 Measurement of mother-infant interactions and the home environment in a European setting: preliminary results from a cross-cultural study M. Gunning, S. Conroy, V. Valoriani, B. Figueiredo, M. H. Kammerer, M. Muzik, E. Glatigny-Dallay, L. Murray and the TCS-PND Group

s45 Health services research into postnatal depression: results from a preliminary cross-cultural study

D. Chisholm, S. Conroy, N. Glangeaud-Freudenthal, M. R. Oates, P. Asten, S. Barry, B. Figueiredo, M. H. Kammerer, C. M. Klier, G. Seneviratne, A.-L. Sutter-Dallay and the TCS-PND Group 